Lancker on hydrolases and cellular death emphasizes how little is known about cell damage and death: whether release of hydrolases is primary or secondary in many instances, and what part the hydrolases play in normal and increased protein turnover.

In general, this book provides a useful account of the current state of knowledge about metabolic conjugation, although much of the ground is already familiar. The three volumes taken together will doubtless provide a standard reference, though the chapters on topics in which ideas are most rapidly changing, for example the role of lysosomes in cell damage, are likely to become dated within a few years.

A. C. Aluison

\section{STUDENT IMMUNOLOGY}

\section{Basic Immunology}

By E. R. Gold and D. B. Peacock, with chapters by J. Verrier Jones, T. E. Blecher, M. O. Symes and W. J. Harrison. Pp. xii +416. (Wright: Bristol, Juno 1970.) $90 s$.

IMMUNOLOGY continues to recruit a steady stream of students at various lovels and from various sources, many of whom, in spite of avowed special interests, sooner or later begin to feel the need for a wider grasp of immunological concepts. A textbook of "basic" immunology might be judged, then, at least in part, by how far it succeeds in meeting this need. The textbooks that have appcared so far (with one or two deservedly well known exceptions) tend to suffer from a plethora induced by the unselective inclusion of too many facts and observations, squeczing out the important consideration of how we are to make the best sense of them in relation to each other, and of how the many questions that follow may best be framed.

This book's success with this problem is less than complete-perhaps because coming from six different pens it forfeits a unified approach. From tho students' standpoint, the best chapters are undoubtedly those on the production of antibody and on cell-mediated immunity and delayed hypersensitivity, which describe some of the most telling experimental and clinical observations, and by critical discussion and pertinent questioning build up a clear picture of present trends in thinking about these two basic immune activities. In another chapter the in vitro correlations of cell mediated immunity are carefully enumerated, but less critically evaluated, so that the "exciting vistas" this work foreshadows show up less clearly than they should.

The chapter on immunoglobulins gives a straightforward account of modern knowledge of their molecular structure and the significance of its variations, but it perhaps assumes too much knowledge or insight in the reader, who, to give one example, might well have some difficulty in grasping the meaning of the Valentine diagram for IgG, given only the background of the text. On the other hand, few students would require the detailed chemical and isomeric analysis of antigenic determinants provided here.

So far as immunopathology goes, there is a useful summary in the section on autoimmunity, which is largely clinical in context. It is in this section that one of the two paragraphs in the book on the biological significance of immune complexes occurs-a surprising lack, because this is a part of immunopathology about which we know something, and which seems now to play an even more important part in disease than was once thought. It is in this section, too, that the subject of immunological tolerance appropriately, though scantily, receives attention. Other aspects of immediate hypersensitivity are discussed elsewhore in the book, and therc are ohapters also on complement, transplantation immunity and tumour immunology. The book is perhaps likely to appeal most to the reader seeking a ready aid in refreshing rather than extending his basic knowledge of immunology.

E. J. HoLboRow

\section{HOUR CLOCKS}

\section{Human Circadian Rhythms}

By R. T. W. L. Conroy and J. N. Mills. Pp. ix +236 . (Churchill: London, 1970.) 60s.

THE more than exponential increase in scientific information causes such bewilderment that many reviews of a field are no more than catalogues of possibly related items. Papers can easily be referred to by the dozen and yet not studied critically for their content and limitations. Human Circadian Rhythms by Conroy and Mills, however, is refreshingly different. The authors have limited their aspirations to what they can reasonably achieve. Their style is direct and clear. It will be only apparent to those familiar with some of the field that the authors have carefully studied the tables and graphs of other authors. In doing so they have been able to assess the significance of the findings and they have wisely erred on the side of demanding real evidence for conclusions.

The book is largely a development of Mills's classical article in Physiological Reviews in 1966. It is at best in the chapter on the kidney. This chapter contains a lucid account of the real difficulties in establishing that, for example, the adrenal cortical rhythms control sodium and potassium excrotion. It is a model for scientific writers.

The work is, in effect, in three parts. After an initial discussion on methods and a critical consideration of the inevitable limits of studies on humans there is an account of the twenty.four hour rhythms established in man and their persistence without time clues and on non-twentyfour hour schedules. This second part is the most detailed and is followed by a concluding and shorter attempt to assess the practical significance of the work which has been carried out.

The writers at every turn occupy themselves with the question of how far the rhythms of the variable discussed are endogenous. They consider the synchronization wnich occurs during development and the interesting desynchronization which can arise from shifts of phase and activity and lightning schedules. There is no evangelism in the whole work. One is left with the findings and the various claims of other writers plus apt comments on the possibility of alternative and more parsimonious views.

The ubiquitous nature of approximately twenty-four hour measuring systems in living organisms, the presumably fundamental nature of the clock-like processes at the molecular level, and the observations dealt with in this book show how far we have already entered a field which will illuminate much in biology. It already seems likely that related processes affect eclosion in Drosophila, the opening and closing of some flowers and the human renal excretion of potassium, and so on. This is relevant to night watchmen's efficiency, to diagnosing Cushing's syndrome, to designs for space flight, and the laying of eggs by chickens.

Conroy and Mills mention very briefly work on the possibility that processes in the production of RNA are the central timing device, and that the hypothalamus in man contains the master clock. The book is, however, chiefly concerned with what has been shown in studies on man himself; the wilder flights of speculation are left for the reader. These he can more aptly pursue after reading an excellont book. 